\title{
Subcellular Localization of miRNAs and Implications in Cellular Homeostasis
}

\author{
Minwen Jie ${ }^{1,2,+} \mathbb{D}$, Tong Feng ${ }^{1,3, \dagger}$, Wei Huang ${ }^{4}$, Moran Zhang ${ }^{5} \mathbb{D}$, Yuliang Feng ${ }^{6, *} \ddagger$, Hao Jiang ${ }^{1, *}$ \\ and Zhili Wen $5, *$
}

check for

updates

Citation: Jie, M.; Feng, T.; Huang, W.; Zhang, M.; Feng, Y.; Jiang, H.; Wen, Z. Subcellular Localization of miRNAs and Implications in Cellular

Homeostasis. Genes 2021, 12, 856. https: / / doi.org/10.3390/ genes12060856

Academic Editors: Enrique

Fuentes-Mattei and

Selvarangan Ponnazhagan

Received: 24 February 2021

Accepted: 28 May 2021

Published: 2 June 2021

Publisher's Note: MDPI stays neutral with regard to jurisdictional claims in published maps and institutional affiliations.

Copyright: (c) 2021 by the authors. Licensee MDPI, Basel, Switzerland. This article is an open access article distributed under the terms and conditions of the Creative Commons Attribution (CC BY) license (https:/ / creativecommons.org/licenses/by/ $4.0 /)$.
1 Laboratory for Aging and Cancer Research, National Clinical Research Center for Geriatrics, West China Hospital, Sichuan University, Chengdu 610041, China; minwenjie1996@foxmail.com (M.J.); fengt9@mail2.sysu.edu.cn (T.F.)

2 Key Laboratory of Transplant Engineering and Immunology, NHC, West China Hospital, Sichuan University, Chengdu 610041, China

3 Key Laboratory of Gene Engineering of the Ministry of Education, State Key Laboratory of Biocontrol, School of Life Sciences, Sun Yat-sen University, Guangzhou 510275, China

4 Department of Pathology and Laboratory Medicine, University of Cincinnati College of Medicine, Cincinnati, OH 45267, USA; huangwe@ucmail.uc.edu

5 Department of Gastroenterology, The Second Affiliated Hospital of Nanchang University, Nanchang 330006, China; simera1996@outlook.com

6 Botnar Research Centre, Nuffield Department of Orthopaedics, Rheumatology and Musculoskeletal Sciences, Old Road, Headington, Oxford OX3 7LD, UK

* Correspondence: yuliangf84@gmail.com (Y.F.); haojiang@scu.edu.cn (H.J.); zhili.wen1972@gmail.com (Z.W.)

$\dagger \quad$ These authors contributed equally.

$\ddagger$ Lead Contact.

Abstract: MicroRNAs (miRNAs) are thought to act as post-transcriptional regulators in the cytoplasm by either dampening translation or stimulating degradation of target mRNAs. With the increasing resolution and scope of RNA mapping, recent studies have revealed novel insights into the subcellular localization of miRNAs. Based on miRNA subcellular localization, unconventional functions and mechanisms at the transcriptional and post-transcriptional levels have been identified. This minireview provides an overview of the subcellular localization of miRNAs and the mechanisms by which they regulate transcription and cellular homeostasis in mammals, with a particular focus on the roles of phase-separated biomolecular condensates.

Keywords: microRNA; subcellular localization; transcriptional regulation; phase separation; condensate

\section{Introduction}

MicroRNAs (miRNAs), a class of evolutionarily conserved endogenous small noncoding RNAs (ncRNAs), contain approximately 20-22 nucleotides. Since their initial discovery, an increasing number of miRNAs have been identified in invertebrates, vertebrates, and plant genomes [1-3], including 2000 miRNAs in the human genome [4]. As the most extensively studied class of ncRNAs, miRNAs play important roles in many cellular biological processes, such as proliferation, differentiation, apoptosis, and stress responses [5,6]. They are key regulators and biomarkers [7-9] of human diseases, such as neurological diseases [10], cardiovascular diseases [11], cancer [12,13], and aging [14]. For example, fragile X syndrome-related miR-125b and miR-132 could modify synaptic strength and regulate synaptic structure [15]. Although miRNAs were initially discovered for their role in cell fate and differentiation decisions during organismal development, they are equally crucial in modulating different homeostasis, including endothelial [16], bone [17], and gut [18]. For instance, miR-876-3p regulates glucose homeostasis and insulin sensitivity by targeting the adiponectin system molecules [18].

MiRNA genes could either be located in intragenic regions and share transcriptional regulatory units with host genes [19-21] or be found in intergenic regions of the genome with independent cis-regulatory elements (CREs) $[19,22,23]$. MiRNA biogenesis typically 
involves processing from primary miRNA transcripts (pri-miRNAs) to precursor miRNAs (pre-miRNAs) and mature miRNAs in the nuclei and cytoplasm (Figure 1). Most miRNAs are canonically transcribed as large pri-miRNAs with a $5^{\prime}$-cap and/or poly-A tail by RNA polymerases II or III in nuclei [24]. Pri-miRNAs are long double-stranded RNAs composed of an apical loop, a stem of $\sim 35$ base pairs, and two flanking single-stranded nucleotides (Belt and Wedge) at the basal end [25]. Then, pri-miRNAs are further cleaved into premiRNAs by a microprocessor complex containing the RNase III enzyme DROSHA and RNA binding protein DiGeorge syndrome critical region 8 (DGCR8) in the nucleus [25,26]. During this cleavage event, the DGCR8 double-stranded RNA binding domain (dsRBD) in the apical half and the DROSHA dsRBD in the basal half form a "double-dsRBD" molecular ruler for an $\sim 35$ base pairs stem region [25]. Moreover, pre-miRNAs with a stem-loop structure are transported from the nucleus to the cytoplasm through the exportin/RanGTP complex [27]. Then, after the removal of an apical loop by the RNase III endonuclease DICER and trans-activation-responsive RNA binding protein (TRBP) $[28,29]$, pre-miRNAs are further processed into a miRNA duplex with a phosphorylated $5^{\prime}$ end and hydroxylated 2 nt $3^{\prime}$-overhang [30]. Next, the miRNA duplex is unwound and the guide strand along with Argonaute (AGO) protein form the miRNA-induced silencing complex (miRISC), binding to the target mRNAs to suppress gene expression [31].

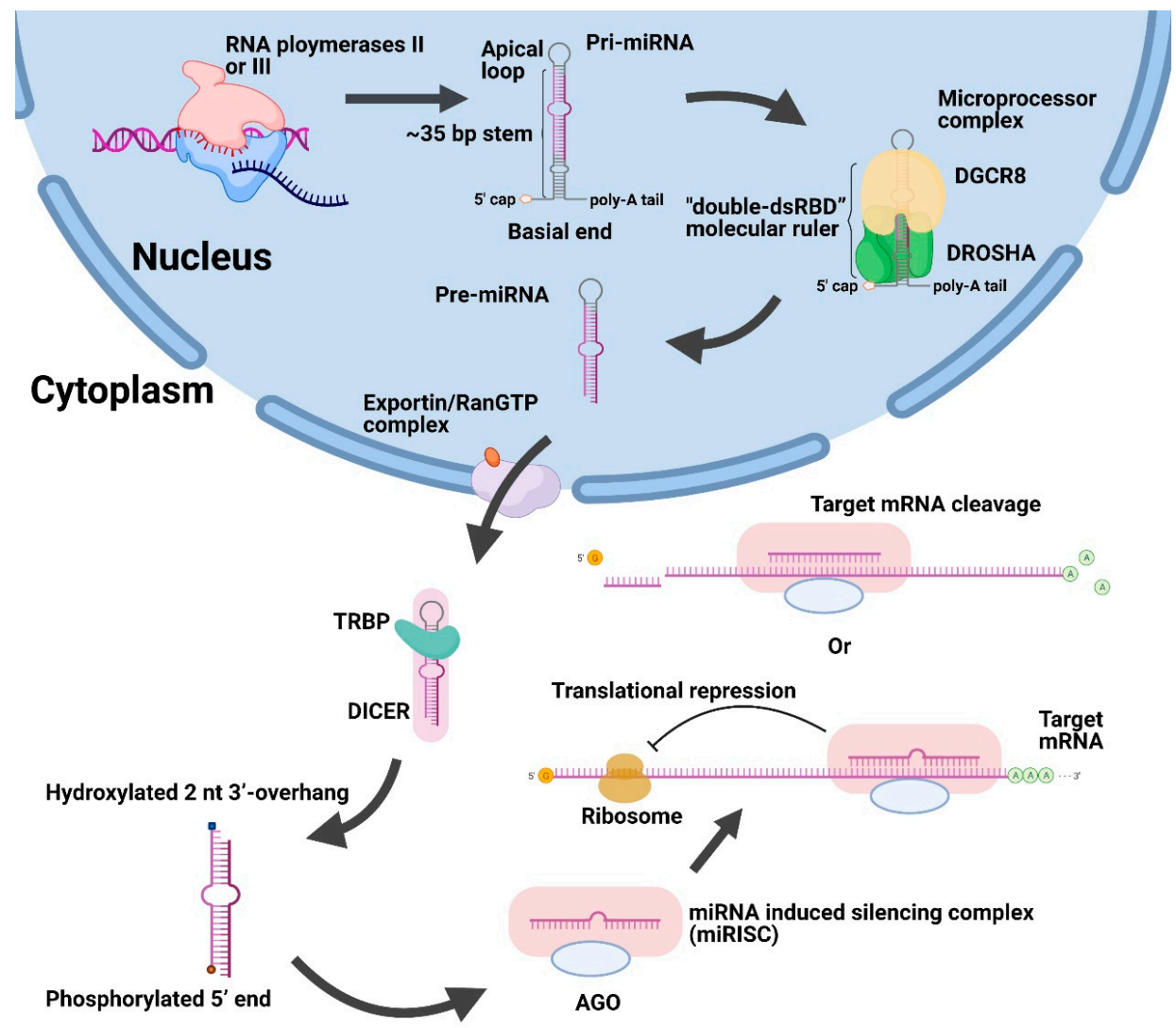

Figure 1. Schematic illustration of canonical biogenesis and function of miRNAs. First, large pri-miRNAs are transcribed by RNA polymerases II or III in the nucleus and then converted into pre-miRNAs after cleavage using the DROSHA/DGCR8 microprocessor complex. Afterwards, the exportin/RanGTP complex exported pre-miRNAs to the cytoplasm. Then, the DICER and TRBP removed the apical loop of pre-miRNAs and unwound the miRNA duplex. After the formation of miRISC, it could suppress the genes by repressing translation or promoting cleavage of target mRNA. Abbreviations: Pri-miRNAs, primary miRNA transcripts. Pre-miRNAs, precursor miRNAs. DGCR8, DiGeorge syndrome critical region 8. TRBP, trans-activation-responsive RNA binding protein. AGO, Argonaute. miRISC, miRNA-induced silencing complex.

MiRNAs were initially thought to regulate gene expression in the cytoplasm [3] negatively. Most studies of the gene regulatory functions of miRNAs have focused on 
sequence-specific mRNA degradation or $3^{\prime}$ UTR "seed-based" translational repression at the post-transcriptional level in the cytoplasm [6]. Nowadays, accumulating data, including small RNA deep sequencing data, has clarified the subcellular location of miRNAs in the nuclei [32] and revealed various novel functions in cellular homeostasis [33]. By unconventional methods, miRNAs could encode small peptides, interact with splicing machinery to regulate gene transcription, and even directly activate target gene transcription [33]. Recently, a study reported that inflammatory miRNAs, including miR-146a, miR-142-3p, and miR-142-5p, are primarily located on mitochondria-associated ER membranes (MAMs) in human and rat brains [34]. Additionally, they showed a distinct distribution pattern in response to inflammatory injury and cell stress [34]. However, the potential roles of miRNA subcellular localization in modulating cellular homeostasis have not been well characterized.

Currently, some researchers have proposed that miRNAs could contribute to the regulation of cellular homeostasis through phase separation $[35,36]$. This means that biomacromolecules such as proteins and RNAs are separated into two phases through weak multivalent interaction [37], especially when fast, large-scale gene expression regulation is needed (e.g., during stress response). Moreover, it was reported that membrane-less compartments could form via phase separation [37]. Furthermore, increasing evidence supports the idea that membrane-less subcellular compartments, collectively called biomolecular condensates, enhance biogenesis [35] and the functioning of miRNAs [37]. For example, AGO2 and GW182 (components of miRISC) proteins could form functional phase-separated condensates to regulate miRNA processing [35]. Elsewhere, it was reported that alternative transcription initiation of DGCR8 could skip stem-loop structures in exons, resulting in a soluble microprocessor phase-separated into insoluble aggregation and finally impeding the expression of global miRNA [37]. This global miRNA dosage control is conserved in the HepG2 and K562 cells and human tissues [37]. Phase separation is not an uncommon phenomenon. However, how the phase-separated condensates function on physiological and biochemical activities remains largely unknown. As a newly emerging concept, phaseseparated condensates have shown great potential to better understand human disease pathogenesis [38,39], including cancer.

Therefore, this review provides a brief overview of the subcellular localization of miRNAs and the mechanisms by which they regulate transcription and cellular homeostasis in mammals, focusing on the phase-separated biomolecular condensate perspective.

\section{Nuclear Localization}

In the past two decades, the nuclear localization of many miRNAs has been wellestablished. Mature miR-21 was first detected in isolated HeLa cell nuclei using quantitative northern blotting [40]. Proteins associated with miRNAs, like the glycine tryptophan protein of $182 \mathrm{kDa}$ (GW182) family protein TNRC6A, have been shown to participate in nuclear miRNA functions [41]. Advances in next-generation sequencing technology have identified numerous miRNAs, mainly enriched in the nucleus. For example, the miR-3535 is enriched in the nucleus via a 27.9-fold over the cytoplasm in murine C116 cells [42]. The high abundance of miRNAs in the nucleus suggests their functional roles in transcriptional and post-transcriptional regulation in cellular homeostasis and human diseases. Recently, nuclear miR-30b-5p was reported to target coordinated lysosomal expression and regulation (CLEAR) elements and negatively regulate lysosomal biogenesis and autophagy in a transcription factor EB (TFEB)-dependent manner [43]. Furthermore, nuclear miR-320 up-regulates CD36 expression by directly activating transcription, whereas the inhibition of nuclear miR-320 could rescue cardiac dysfunction in diabetic mice [44,45]. This section has mainly described the molecular mechanisms underlying the effects of nuclear miRNAs during transcription regulation.

\subsection{Nuclear miRNAs Acting on Cis-Regulatory Elements (CREs)}

Recent studies demonstrated that miRNAs located in the nucleus could act on CREs (e.g., promoters and enhancers) to regulate gene expression (activation or suppression) 
(Figure 2). For example, the nuclear miR-665 binds directly to the PTEN promoter and suppresses its transcription, promoting heart failure [46]. Nuclear miR-320 can bind to the promoters of multiple genes (CEP57, SORBS3, MEX3A, FSCN2, PTGIR, VPS37D, etc.), activating their transcription [47]. MiR-320 translocates from the cytosol into the nucleus, binds to the promoter of CD36 and promotes its transcription, thereby increasing lipid deposition in hepatocytes [48]. Nuclear miR-373 and miR-744 can bind the CDH1 (E-cadherin) and CCNB1 (cyclin B1) promoters, respectively, to induce expression and modulate tumor growth [49]. However, the precise mechanism in which miRNAs upregulate or down-regulate gene expression by targeting promoters remains unclear. A recent report suggested the potential roles of the interaction of AGO and nuclear miRNAs. For example, the miR-133a/AGO2 complex binds to the DNMT3B promoter, stimulating promoter methylation using DNMT3B [50]. The knockdown of AGO2 attenuates the miR-665-mediated PTEN up-regulation in H9c2 cells [46]. In addition, the expression of nuclear AGO rescues CD36 overexpression caused by the direct binding of miR-320 to the CD36 promoter [44]. However, based on the DNA-RNA hybrid, some researchers have argued that AGO could not be necessary for miRNA-promoter interactions [51,52]. For example, Zhang et al. reported that let-7i directly targeted the TATA-box region of the IL-2 promoter [52]. Thus, miRNAs directly interact with the DNA promoter, providing another possible mechanism independent from AGO for miRNA-promoter interactions. Hence, the precise roles of AGO in miRNA-mediated transcription require further investigation.

Apart from promoter binding, nuclear miRNAs could also act on enhancers to activate transcription (Figure 2B). Enhancer triggering nuclear activating miRNAs (ET-NamiRNAs), bound on active enhancers marked by histone H3K27ac, P300/CBP, and DNase I highsensitivity loci, were first described in 2017 [53]. ET-NamiRNAs could promote the transcription of homologous genes distributed across the genome. This process could regulate cell reprogramming and induce tumorigenesis [44,54]. As validated through the luciferase assay, miR-26a-1 activates enhancers to up-regulate neighboring genes, such as ITGA9 and VILL [53]. Moreover, miR-3179 and miR-3180 are located in the same chromosomal region next to $A B C C 6$ and $P K D 1 P 1$. While the miR-3179 with enhancer activity up-regulated the neighboring genes $A B C C 6$ and $P K D 1 P 1$, the miR-3180 without the enhancer activity failed to activate these genes [53]. Furthermore, miR-24-1 promoted the expression of neighboring FBP1 and FANC genes. The overexpression of this miRNA depended on AGO2, which was functioned by enriching the RNA Pol II and altering the chromatin accessibility of enhancers and promoters [53]. Furthermore, super-enhancers (SEs) and transcription factors (TFs) exert cell type-specific effects on miRNA processing. The SEs recruit DROSHA/DGCR8 and promote pri-miRNA processing, networking with miRNAs in at least 18 cancer cells [55]. Generally, miRNAs interact with enhancers to modulate gene expression and cellular homeostasis. However, the molecular mechanism underlying miRNA-enhancer interactions and functions remain obscure.

Condensates formed by phase separation influence transcription. For example, the coactivators MED1 and BRD4 form nuclear puncta at SEs in mouse embryonic stem cells. Condensates formed by the intrinsically disordered region of MED1 (MED1-IDR) attract BRD4 and RNA Pol II and squelch in vitro transcription with nuclear extracts [56]. Interestingly, the miRNA-related protein GW182 undergoes phase separation in GFP-GW182overexpressing HEK293 cells [35]. Moreover, AGO2 and GW182 form phase-separated condensates through in vivo and in vitro setups, as confirmed using fluorescence recovery after photobleaching (FRAP) and fusion assays [35]. Furthermore, the AGO2-GW182 condensate recruited miRISC-associated proteins and promoted the deadenylation of target RNAs [35]. Based on AGO2 and GW182 nuclear locations, miRNA-associated proteins (e.g., AGO2) could modulate transcription through phase separation on CREs. Young and colleagues reported that nuclear condensates formed using TFs and coactivators, including MED1, could include or exclude small molecules, providing a basis for developing therapies against chemoresistant cancer [57]. Based on these previous findings, we have proposed a model for the effects of nuclear miRNAs on CREs (Figure 3). First, nuclear 
miRNA-associated miRISC components, such as AGO2 and GW182, undergo phase transitions to form condensates at targeted CREs. On the one hand, specific RNA molecules (e.g., lncRNAs and miRNAs) and proteins (e.g., TFs, RNA Pol II, and chromatin remodeling complexes) could be recruited to facilitate or impede transcription by promoting transcription initiation and elongation or remodeling chromatin. On the other hand, the condensates could exclude the transcription activation machinery that down-regulates gene expression.

A

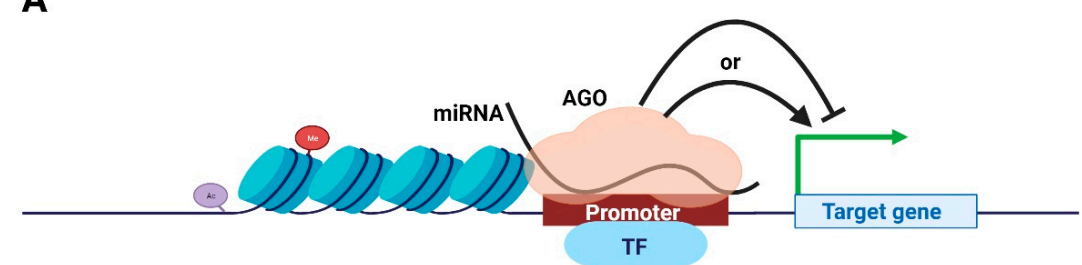

B
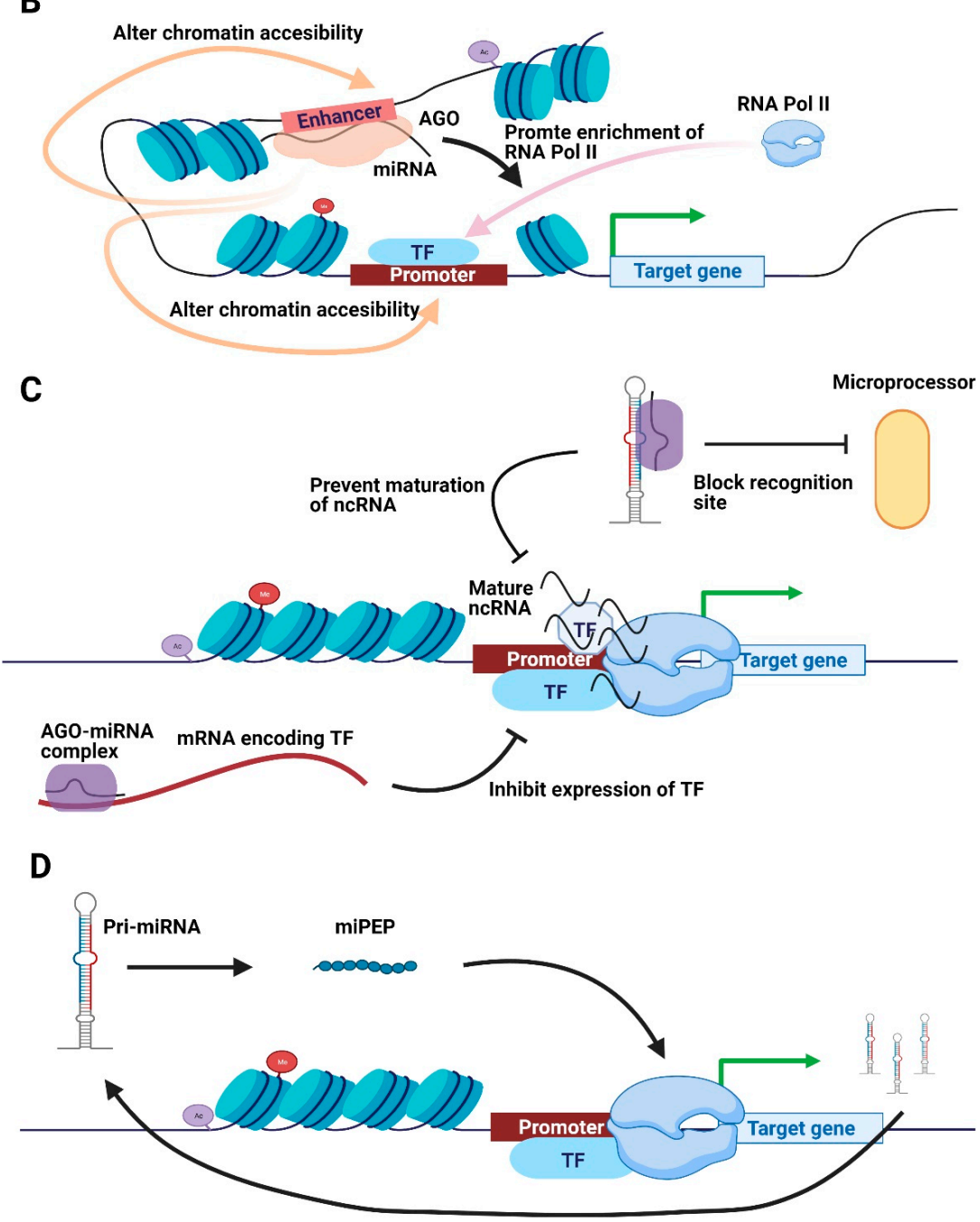

Figure 2. Schematic illustration of transcriptional regulatory mechanisms of nuclear miRNAs. (A) Nuclear miRNA directly binds onto the promotor to promote or impede transcription in an AGO-dependent manner. (B) Nuclear miRNA and AGO directly bind to the enhancer to enrich RNA Pol II or alter chromatin accessibility, promoting transcription. (C) MiRNA inhibits TF expression to suppress transcription, whereas the AGO-miRNA complex blocks the maturation of ncRNA to impede transcription. (D) PrimiRNA encodes short peptides to simulate transcription of responding pri-miRNA. Abbreviations: AGO, Argonaute. TF, transcription factor. miPEP, miRNA-encoded peptide. 
MiRNAs acting on CREs provide new targets and strategies for preventing and treating of cancer and other human diseases. This emphasizes the importance of further investigations of the interactions between miRNAs and CREs and their biological and physiological functions in cellular homeostasis and human diseases.
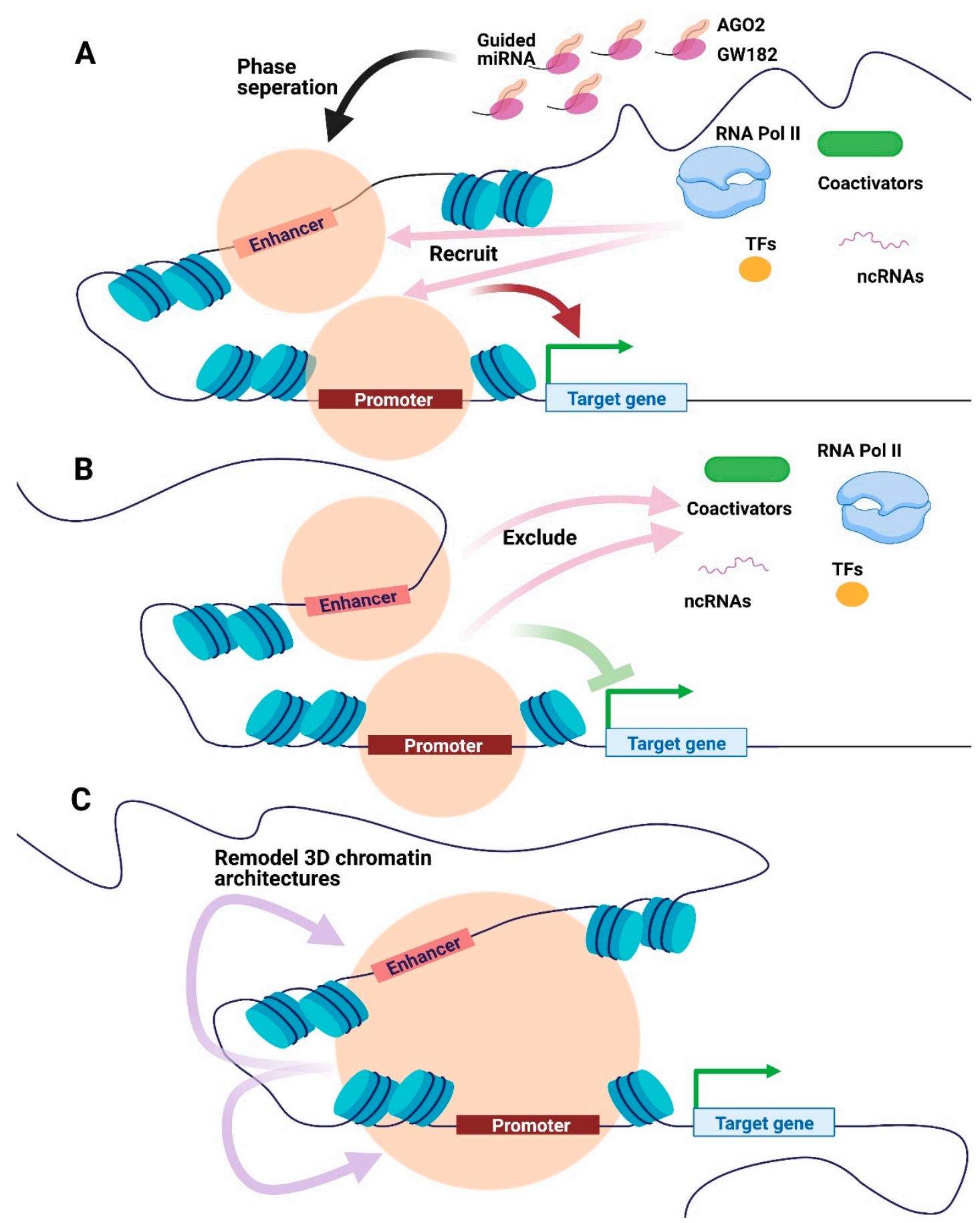

Figure 3. Potential models of miRNA-mediated condensates in transcriptional regulation. (A) AGO2, GW182, and guided miRNA could be phase-separated at the promoter or enhancer regions to recruit transcriptional apparatus, including RNA Pol II, TFs, coactivators, and ncRNAs, promoting transcription. (B) Condensates consist of AGO2, GW182 and guided miRNA may exclude transcriptional biomolecules, hence impeding transcription. (C) The miRNA-mediated condensates could remodel 3D chromatin architectures to regulate transcription. Orange circles represent condensates formed by phase separation. Abbreviations: AGO, Argonaute. RNA Pol II, RNA polymerase II. TFs, transcription factors. ncRNAs, non-coding RNAs. 


\subsection{Other Potential Pathways for Nuclear miRNAs to Regulate Transcription}

Beyond direct interactions with CREs, other potential pathways, including the regulation of RNAs, peptide activity, and chromatin remodeling [58], for transcriptional regulation through nuclear miRNAs, have emerged.

The ability of miRNAs to silence the expression of TFs has been established. For example, miR-9 suppresses the expression of peroxisome proliferator-activated receptor $\delta$ (PPAR- $\delta$ ), which binds to the $3^{\prime} \mathrm{UTR}$ of PPAR- $\delta$ mRNA, as validated using a luciferase assay in human monocytes [59]. Apart from the cytoplasm, miRNAs also exert posttranscriptional gene silencing in the nucleus. Research has reported that miR-9 directly targets metastasis-associated lung adenocarcinoma transcript 1 in the nucleus and degrades it in an AGO2-dependent manner [60]. Nuclear miR-122 has been shown to prevent the maturation of pri-miR-21 by directly binding on it, thus blocking the recognition region of the DROSHA-DGCR8 microprocessor, promoting liver cell apoptosis [61]. Similarly, miRNA-709 impedes miRNA-15a/16-1 biogenesis to regulate apoptosis in mouse cells [62]. Based on different RNA-mediated transcription studies [63,64], we speculate that nuclear miRNAs could indirectly modulate transcription by degrading genes encoding TFs and preventing the maturation of ncRNAs (Figure 2C).

Interestingly, pri-miRNAs produce peptides, called miRNA-encoded peptides (miPEPs), which upregulate the transcription of these pri-miRNAs. For example, pri-miR-171b in Medicago truncatula and pri-miR-165a in Arabidopsis thaliana were first described to function as template-encoding peptides of nine and 18 amino acids, respectively [65]. Moreover, these two miPEPs participate in root development by up-regulating their pri-miRNAs, resulting in mature miRNA accumulation and the down-regulation of target genes [65]. Furthermore, five other miPEPs in M. truncatula and A. thaliana [65] and two other miPEPs (miPEP-200a and miPEP-200b) in prostate cancer cells [66] have been identified. A miR-34a pri-miRNA encoded miPEP133 was identified in many human tissues, including colon, stomach, ovary, uterus, and pharynx and during regulated apoptosis, invasion, and migration of cancer cells [54]. Collectively, these data suggested that miRNAs could encode short peptides miPEPs as new factors during transcription regulation (Figure 2D).

Increasing evidence suggests that RNAs contribute to the organization of the 3D chromatin structure [64]. For example, nascent RNA-induced R-loops are enriched with TFs and chromatin remodeling factors in mouse embryonic stem cells to impair differentiation [67]. Moreover, the miRNA lethal 7-mediated multicomponent RNA-protein complex (MiCEE), including polycomb repressive complex 2 (PRC2), induces heterochromatin and silences transcription [58]. Interestingly, mutation of RNA-binding regions in CTCF (a critical architectural protein) drastically disrupted chromatin looping and impeded gene expression [68], suggesting that the chromatin-associated RNAs (e.g., nuclear miRNA) could be involved in their 3D genome organization (Figure 3C). Further, a number of droplet-like condensates are associated with RNAs, partly because most proteins involved in phase separation are RNA-binding proteins $[63,69,70]$. Therefore, it is imperative to use phase separation or other mechanisms in the future to explore whether nuclear miRNA modulates chromatin topology.

\section{Membrane Compartments}

Membrane compartments are functional subcellular organelles surrounded by membranes that mainly consist of lipids and proteins. By participating in the material exchange, and energy and information transfer process, membrane compartments play essential roles in promoting cell survival, growth, division, and differentiation, thereby maintaining homeostasis of the intracellular microenvironment. Notably, the most crucial membrane compartments associated with miRNAs are mitochondria and endoplasmic reticulum (ER) (Figure 4). 


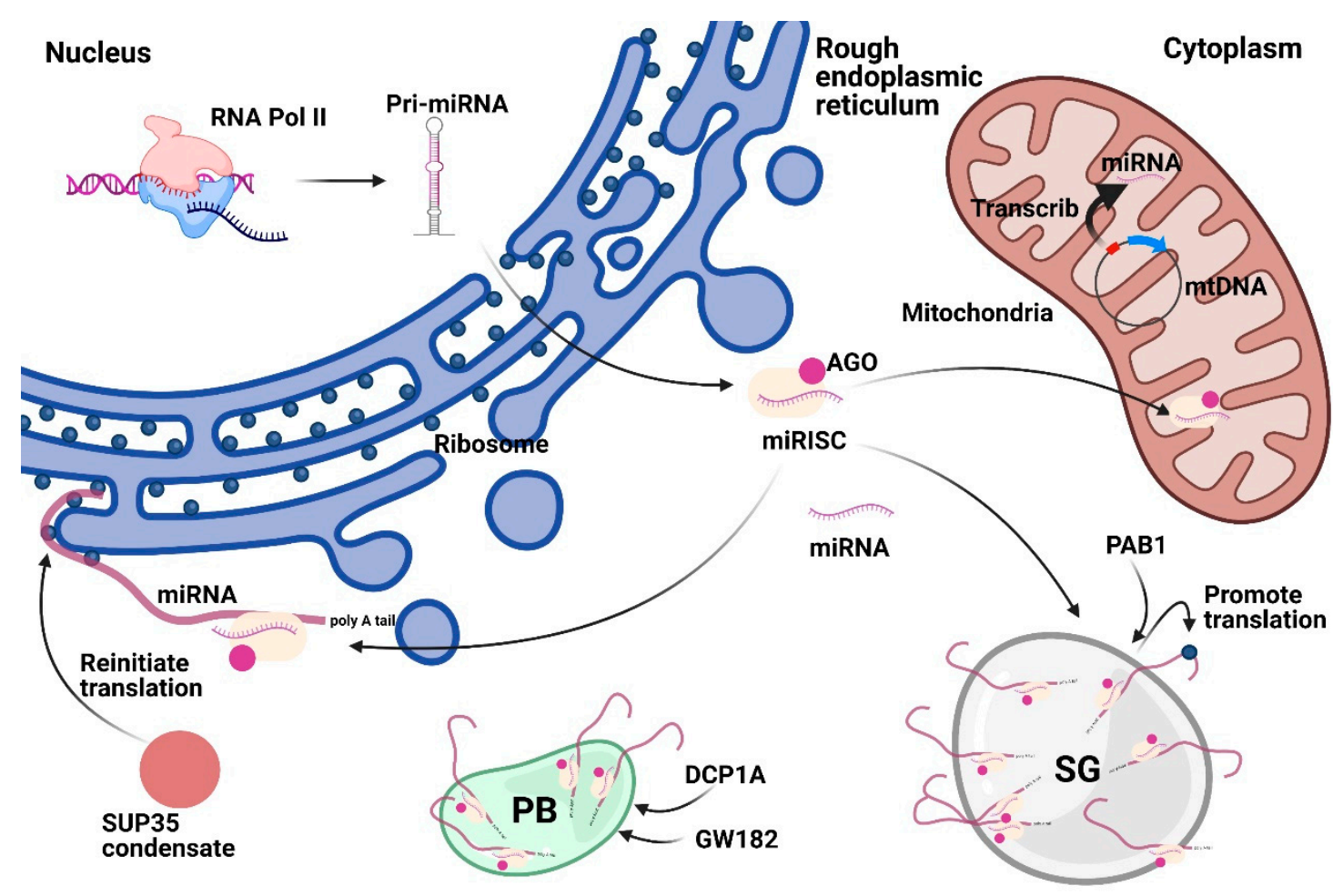

Figure 4. Subcellular localization of Cytoplasmic miRNAs. Cytoplasmic miRNAs could localize in membrane compartments (mitochondria and ER) or membrane-less compartments (SG and PB). In rough ER, miRNA could regulate mRNA translation. Mitochondrion-derived MitomiRs could be encoded from mtDNA or be translocated from the cytoplasm. SG marker PAB1 could promote translation. GW182 and DCP1A could induce PB formation to regulate the function of miRNA. SUP35 could form condensate to reinitiate translation. Abbreviations: AGO, Argonaute. ER, endoplasmic reticulum. SG, stress granule. PB, processing body. MitomiRs, Mitochondrial miRNAs. mtDNA, mitochondria DNA. PAB1, poly(A)-binding protein 1. GW182, glycine tryptophan protein of $182 \mathrm{kDa}$. DCP1A, decapping mRNA 1A.

\subsection{Mitochondria}

Mitochondria are double membrane-bound cellular compartments in eukaryotic cells with a central role in cellular homeostasis and human diseases. As the primary sites for redox reactions and ATP production, mitochondria have a genome similar to bacterial chromosomes. The human mitochondria DNA (mtDNA), with 16,000 base pairs length, encodes only 13 proteins ( 1\% of all proteins) [71]. However, the mtDNA encodes abundant small non-coding RNAs [72] (e.g., the majority of mitochondrial tRNAs are encoded by mtDNA) [73]. In the purified human 143B cell mitochondria, several small RNAs mapped to mtDNA have been identified using small RNA sequencing, without the DICERdependent characteristic of nuclear tRNAs [74]. Moreover, through Sanger sequencing, small RNA RT-PCR, and PCR amplification of mouse and human small RNA libraries, Ro et al. demonstrated that the mitochondrial genome encodes small RNAs (mitosRNAs). These included miRNAs with $5^{\prime}$ phosphate termini different from the $5^{\prime}$ termini of RNA turnover products [72]. However, due to the absence of miRNA processing proteins, such as DROSHA, in the mitochondria, the processing and function of miRNAs transcribed from mtDNA have not been well understood.

Additionally, nuclear miRNAs in different species have been shown to localize and function in the mitochondria. For instance, a qPCR analysis verified that the miR-4485 levels in the mitochondria are more than two-fold higher than those in whole HEK293 cells, using U6 snRNA as the endogenous control [75]. Additionally, the levels of precursor miR-4485 in the cytosol were approximately six times higher than those of precursor miR4485 in the mitochondria [75]. Furthermore, in HEK293 cells, the miR-4485 levels were reduced by the deleting mtDNA using bromide treatment, and mitochondrial miR-4485 was down-regulated when cytoplasmic translocation was inhibited using Leptomycin 
B [75]. Nuclear miR-181c is translocated to mitochondria in cardiac myocytes [76]. Although possible models explaining the miRNAs translocation into the mitochondria have been proposed [77] (Table 1), the specific mechanism and biological significance of this translocation are yet to be established.

Table 1. Possible mechanism of miRNAs translocation into mitochondria.

\begin{tabular}{|c|c|c|}
\hline Candidated miRNA & Potential Mechanism & Reference(s) \\
\hline \multirow[t]{2}{*}{ let-7a } & $\begin{array}{l}\text { Posttranslational modification of AGO2 promotes the AGO2 and miRNA } \\
\text { complex intake into P-body, which could translocate them into mitochondria. }\end{array}$ & {$[78,79]$} \\
\hline & $\begin{array}{l}\text { Without AGO2, miRNAs may translocate separately into mitochondria through } \\
\text { SAM50 and/or TOM. }\end{array}$ & {$[73,77,80]$} \\
\hline miR-1 & $\begin{array}{l}\text { AGO2 and miRNA complex from miRISC is transported into mitochondria after } \\
\text { changes of GW182 and/or HDAC4. }\end{array}$ & [81] \\
\hline mitomiR-378 & $\begin{array}{c}\text { Polynucleotide phosphorylase (PNPase) helps import the AGO2 and miRNA } \\
\text { complexes into the mitochondria. }\end{array}$ & {$[23,82,83]$} \\
\hline
\end{tabular}

Abbreviations. AGO, Argonaute. SAM50, sorting assembly machinery 50 kDa subunit. TOM20, Mitochondrial import receptor subunit TOM20. GW182, glycine tryptophan protein of $182 \mathrm{kDa}$.

Mitochondrial miRNAs (MitomiRs) play vital roles in the regulating mitochondrial function in human diseases, such as cancer. For instance, Fan et al. reported that mitomiR2392 disrupts the metabolic balance between downregulated oxidative phosphorylation (OXPHOS) and upregulated glycolysis in cisplatin-resistant tongue squamous cell carcinoma cells and tumors [84]. MitomiRs contribute to diseases mainly through mitochondriamediated processes, such as apoptosis and energy metabolism. For example, mitochondrial miR-762 was reported to regulate redox reactions and ATP production in the mitochondria and to promote apoptosis via NADH dehydrogenase subunit 2 (ND2) in cardiomyocytes [85]. Similarly, mitochondria-targeted miR-4485 regulates mitochondrial metabolism and apoptosis in breast carcinoma cells [75]. Thus, future studies on specific mechanisms underlying mitomiR distribution and functions could identify new drug delivery routes and mitochondrial biomarkers to treat mitochondria-based human diseases.

\subsection{Endoplasmic Reticulum}

ERs, with numerous metabolic functions, have crucial roles in protein assembly and secretory pathways. In addition, the ER has vital roles in $\mathrm{Ca}^{2+}$ storage and lipid and sterol biosynthesis. Rough ER is enriched with membrane-attached ribosomes, which are the primary sites for translating different proteins such as membrane-spanning, secreted, and soluble proteins [86]. Of note, AGO1-miRNA complexes were found to co-sediment with ribosomes in both iodixanol gradient and sucrose gradient centrifugation assays [87]. Moreover, using the parallel analysis of RNA ends (PARE) technique, Yang et al. reported that miRNA-guided target cleavage events were pervasive in ribosome-associated $\mathrm{mR}$ NAs of maize and rice [88]. For example, the PARE assay suggested that miR-2118 and miR-2275 levels are higher in membrane-bound polysomes than in total polysomes and cleaved 21PHAS and 24PHAS precursors in tassels and panicles [88]. Taken together, ER-membrane-attached ribosomes could enrich miRNA and provide a place for miRNAguided target cleavage.

Recently, miRNAs have been implicated in regulating ER stress, in which the disturbance of protein translation, modification, and degradation was caused by extracellular and/or intracellular stress. For example, ER stress in HUVECs caused by tunicamycin treatment resulted in the up-regulation of miR-204, and, conversely, treatment with a miR204 inhibitor could prevent the ER stress [89]. The specific mechanism by which miRNAs contribute to the ER stress response is complicated and studies have largely primarily focused on protein folding, modification and the unfolded protein response (UPR). An in-silico analysis and luciferase assay identified miR-224 and miR-520c as suppressors of tumor suppressor candidate 3 (TUSC3), related to tumor procession [90]. The knockdown of 
TUSC3 in orthotopic xenograft mice promoted lung cancer metastasis, which was rescued through anti-miR-224/520c miRNAs treatment [90]. Moreover, recent study suggested that the ER stress-induced UPR sensor activating transcription factor 6 alpha (ATF6 alpha) influenced UPR activation under ER stress, triggered by a TUSC3 deficiency [90]. This was not the case in protein kinase R-like endoplasmic reticulum kinase (PERK) and inositol requiring enzyme 1 alpha (IRE1 alpha). Furthermore, the activation of ATF6 depended on the Cys-X-X-Cys motif, in which TUSC3 promoted the N-linked glycosylation of proteins [90]. Taken together, miR-224 and miR-520c suppressed TUSC3 expression to induce ER stress and impeded the glycosylation of ATF6 $\alpha$ to block ER stress-induced UPR. More recently, it has been reported that ER stress induces the expression of miR-26a. By directly binding to eukaryotic initiation factor 2 alpha (eIF2 alpha), miR-26a moderates ER stress and lipid accumulation in non-alcoholic fatty liver disease [91]. The overexpression of miR-204 down-regulates Sirtuin1 and promotes ER stress, along with the accumulation of abnormally acetylated proteins [89].

Additionally, ER-related miRNAs play a crucial role in cancer proliferation, metastasis and apoptosis. For example, the overexpression of miR-328-3p, targeting ER metalloprotease 1 (ERMP1), prevented liver cancer cell proliferation and invasion in female nude mice by reducing phosphorylation [92]. RT-qPCR analyses of biopsy specimens and cell lines verified that miR-370 is upregulated in gastric cancer, and Circ_002117 inhibits miR-370 to stimulate ER stress-induced apoptosis [93]. Moreover, ER stress-induced exosomal miRNAs also contribute to the pathogenesis of cancer. For example, ER stress increased the release of exosomal miR-23a-3p from hepatocellular carcinoma (HCC) cells, promoting HCC genesis via the upregulation of PD-L1 in macrophages [94]. Furthermore, exosomal miR-27a-3p induced through ER stress has been found to activate macrophages by targeting MAGI2 to upregulate PD-L1. The activated macrophages inhibit CD8+ T cells from promoting immune escape in breast cancer [95].

In summary, miRNAs play significant roles in promoting the biochemical function of the ER, including RNA cleavage, protein modification and the UPR. Given the diverse roles of the ER in maintaining homeostasis, it is reasonable to assume that ER stress-induced miRNAs are considerably critical during environmental stress responses.

\subsection{Endosomal Trafficking}

miRNAs are found in the endosomal trafficking pathways, including GW-bodies, multivesicular bodies (MVBs), and endosomes [96-98]. Lee et al. suggested that MVBs enhanced the miRNA-guided silencing by promoting recycling of miRISC and contributes to the recruitment of miRNAs to miRISC [96]. Either blocking the formation of MVBs or promoting MVBs to form lysosomes could impair silencing mediated by miRNAs [96]. Except for the recycling model, the cellular trafficking system provides sufficient space for a more distal regulation of miRNA-related silencing. Corradi et al. proposed that pre-miRNAs could be trafficked to distal axons with the help of lysosomes/late endosomes to be processed into mature miRNAs in the distal axon to repress mRNA translation [98]. Collectively, the endosomal trafficking pathway could control the distribution and function of miRNAs.

\section{Membrane-Less Compartments}

In addition to membrane compartments, many membrane-less compartments are formed through phase separation and are involved in cellular homeostasis. Cells have evolved elaborate cellular stress response mechanisms to maintain homeostasis and protect them against stress, including cell repair and cell death [99]. These responses require massive and rapid gene expression regulation at the transcriptional and/or post-transcriptional level. Cells must activate complex response mechanisms over a short time to fight against extracellular stress. Unfortunately, such a "battle" itself is a burden to cells and is likely to cause cell damage. Therefore, it is a challenge to optimize extracellular and intracellular processes while minimizing costs in cells. Accumulating evidence has demonstrated 
that membrane-less subcellular compartments associated with miRNAs are efficient and convenient tools for maintaining homeostasis.

In the cytoplasm, stress granules (SGs) are among the most extensively studied miRNA-associated membrane-less compartments. SGs, mainly comprising mRNAs and RNA-binding proteins, are cytoplasmic membrane-less compartments regulating mRNA translation and defend against cellular stress to maintain homeostasis [100]. Moreover, SGs are formed through phase separation [101]. Recently, interactions between SGs and miRNAs have been identified. As determined using mass spectrometry, interactions between HSP90 and the co-chaperone p23 with DICER as well as interactions between SG-associated proteins, such as AGO2, and/or DICER increased under stress [102]. Moreover, the stressinduced interactions between SGs and miRNA-related proteins (AGO2 and DICER) could regulate miRNA biogenesis by attenuating DICER catalytic activity [103]. Conversely, in acute ischemic stroke rats model of middle cerebral artery occlusion (MCAO), miR-335 promoted SG formation by downregulating ROCK2 [103]. Further, miR-335 directly targeted the ROCK2 3' UTR to inhibit apoptosis in PC12 cells [104]. Interestingly, in ischemic cortices of MCAO rats, METTL3, m6A, and miR-335 were up-regulated at $0 \mathrm{~h}$ after reperfusion but significantly down-regulated at $24 \mathrm{~h}$ after reperfusion [104]. This was similar in PC12 cells treated with oxygen-glucose deprivation/reperfusion (OGD/R) stimulation as an in vitro model of acute ischemic stroke [104]. Furthermore, METTL3-mediated m6A modifications of pri-miR-335 promoted the mature miR-335 expression, enhancing SG formation and attenuating apoptosis in OGD/R stimulated PC12 cells. DCP1A and GW182 were reported to enhance miRNA regulation of targets by inducing the formation of processing bodies and GW bodies [105]. Overall, miRNA interactions with components of cytoplasmic membrane-less compartments could be involved in cellular homeostasis. Conversely, cytoplasmic membrane-less compartments induced by environmental stress could regulate miRNA biogenesis and functions in human diseases.

Processing bodies (PBs) are other prominent cytoplasmic membrane-less compartments, mainly consisting of mRNAs, mRNA cleavage enzymes, and RNA transport factors [106]. In response to stress, PBs interact with SGs and increase their size and number $[99,106]$. In addition, PBs could intake complex phosphorylated AGO2 [78] and translocate them into mitochondria. More recently, dicing bodies in plants have been regarded as protein condensates formed using phase transitions. During an in vitro setup, SERRATE forms liquid-like droplets to recruit DCL1, HYL1, and pri/pre-miRNAs, promoting the processing activity, maturation, and export of miRNAs [107].

Except for well-known miRNA-related membrane-less compartments, various RNArelated subcellular biomolecular condensates are crucial in resisting environmental disturbances. For example, the SG marker poly(A)-binding protein (PAB1) forms condensates to sense thermal or $\mathrm{pH}$ stress and maintains yeast fitness by promoting mRNA translation [108]. A study reported that condensates formed by the translation termination factor Sup35 could rescue the catalytic $C$ domain to preserve the rapid recovery of yeast by reinitiating mRNA translation [109]. In addition to RNA translation, some biomolecular condensates modulate transcription and RNA splicing. Surprisingly, when phosphorylated by CDK7 and CDK9 at the C-terminal domain, RNA Pol II promotes the switch from condensates involved in transcription initiation to condensates related to RNA splicing [110]. Moreover, Henninger et al. proposed an RNA-mediated no-equilibrium feedback model of transcriptional regulation. The model suggested that small amounts of RNA promoted transcription but a large amount of RNA impeded the process [63]. This research shows the possibilities of miRNA-related membrane-less compartments in maintaining cellular homeostasis.

In conclusion, membrane-less compartments and biomolecular condensates could regulate miRNA biogenesis. Further, in cooperation with membrane-less compartments and biomolecular condensates, miRNAs could modulate homeostasis for many biological and physiological processes, including transcription and apoptosis. However, the distribution of miRNAs to these compartments and the specific mechanisms underlying 
the regulatory effects of membrane-less compartment-related miRNAs on biochemical reactions and biological processes are largely unidentified.

\section{Conclusions and Perspectives}

Since the discovery of miRNAs, their subcellular localization has been largely ignored owing to technical limitations. Although some technical difficulties remain in isolating pure subcellular fractions and in precise immunofluorescence-based localization analyses, accumulating research has provided a broad view of the subcellular localization of miRNAs and novel miRNA functions, especially in nuclei. By studying the mechanisms by which nuclear miRNAs contribute to transcriptional regulation, we encountered a highly complicated network of miRNA-DNA-protein interactions. By directly binding to promotors or enhancers, miRNAs can either promote or inhibit gene expression; however, the specific underling mechanism and molecular pathways are not well-established. We hypothesize that the concept of phase separation may provide a framework for transcriptional regulation by miRNAs. First, the miRNA-related proteins AGO2 and GW182 can form functional condensates [35] and chromatin remodeling factors SWI2/SNF2 can impede pri-miRNA processing [111], suggesting that biomolecular condensates regulate miRNA processing and functions. Moreover, RNA-mediated transcriptional condensates have been verified to modulate transcription initiation and elongation and alter splicing [110]. Furthermore, chromatin-associated RNAs have been implicated in the organization of the 3D genomic structure $[63,64]$, which may partially depend on transcriptional condensates. Taken together, it is likely that miRNAs regulate transcription via phase transitions. Given the fact that bio-condensates are pervasive in cancer cells, strategies related to miRNA-mediated bio-condensates may provide a promising new direction for cancer prevention and therapy.

MitomiRs and ER-located miRNAs may be necessary for the modulation of specific biological processes and tumorigenesis. In addition, miRNAs have been detected in cytoplasmic membrane-less compartments, such as SGs, and these miRNAs are of great significance for cell fitness. However, the organization, trafficking and functions of miRNAs located in different subcellular compartments are largely unknown. Thus, these topics should be further addressed in the future, which could provide novel insights into the development of miRNA-based therapies for human diseases, such as cancer.

Author Contributions: Conceptualization, M.J., T.F. and Y.F.; Literature Search, M.J., T.F., W.H., M.Z. and Y.F.; Figure Sketching, M.J. and T.F.; Writing and Editing, M.J., T.F. and Y.F.; Supervision, Y.F. and H.J. and Z.W. All authors have read and agreed to the published version of the manuscript.

Funding: Y.F. is supported by Clarendon Fund, UK (Grant No. SFF1920_CB_MSD_759707). H.J. is supported by 1.3.5 Project for Disciplines of Excellence, West China Hospital, Sichuan University (Grant No. ZYYC20001), National Clinical Research Center for Geriatrics, West China Hospital, Sichuan University (Grant No. Z20191011), National Key Research and Development Program of China (Grant No. 2018YFA0108302), National Natural Science Foundation of China (Grant No. 32090043) and National Natural Science Foundation of China (Grant No. 31771505). Z.W. is supported by National Natural Science Foundation of China (Grant No. 82070594).

Institutional Review Board Statement: Not applicable.

Informed Consent Statement: Not applicable.

Data Availability Statement: Not applicable.

Conflicts of Interest: The authors declare no conflict of interest.

\section{References}

1. Li, S.; Li, M.; Liu, K.; Zhang, H.; Zhang, S.; Zhang, C.; Yu, B. MAC5, an RNA-binding protein, protects pri-miRNAs from SERRATE-dependent exoribonuclease activities. Proc. Natl. Acad. Sci. USA 2020, 117, 23982-23990. [CrossRef]

2. Millar, A.A.; Waterhouse, P.M. Plant and animal microRNAs: Similarities and differences. Funct. Integr. Genom. 2005, 5, $129-135$. [CrossRef] 
3. Lee, R.C.; Feinbaum, R.L.; Ambros, V. The C. elegans heterochronic gene lin-4 encodes small RNAs with antisense complementarity to lin-14. Cell 1993, 75, 843-854. [CrossRef]

4. Kozomara, A.; Birgaoanu, M.; Griffiths-Jones, S. miRBase: From microRNA sequences to function. Nucleic Acids Res. 2019, 47, D155-D162. [CrossRef] [PubMed]

5. Dexheimer, P.J.; Cochella, L. MicroRNAs: From Mechanism to Organism. Front. Cell Dev. Biol. 2020, 8, 409. [CrossRef]

6. Gebert, L.; MacRae, I.J. Regulation of microRNA function in animals. Nat. Rev. Mol. Cell Biol. 2019, 20, 21-37. [CrossRef]

7. Shin, V.Y.; Siu, J.M.; Cheuk, I.; Ng, E.K.; Kwong, A. Circulating cell-free miRNAs as biomarker for triple-negative breast cancer. Br. J. Cancer 2015, 112, 1751-1759. [CrossRef] [PubMed]

8. Zhang, J.X.; Song, W.; Chen, Z.H.; Wei, J.H.; Liao, Y.J.; Lei, J.; Hu, M.; Chen, G.Z.; Liao, B.; Lu, J.; et al. Prognostic and predictive value of a microRNA signature in stage II colon cancer: A microRNA expression analysis. Lancet Oncol. 2013, 14, 1295-1306. [CrossRef]

9. Singla, N.; Lafin, J.T.; Bagrodia, A. MicroRNAs: Turning the Tide in Testicular Cancer. Eur. Urol. 2019, 76, 541-542. [CrossRef]

10. Wang, J.; Cao, Y.; Lu, X.; Wang, T.; Li, S.; Kong, X.; Bo, C.; Li, J.; Wang, X.; Ma, H.; et al. MicroRNAs and nervous system diseases: Network insights and computational challenges. Brief. Bioinform. 2020, 21, 863-875. [CrossRef]

11. Cakmak, H.A.; Demir, M. MicroRNA and Cardiovascular Diseases. Balk. Med. J. 2020, 37, 60-71. [CrossRef]

12. Xing, S.; Tian, Z.; Zheng, W.; Yang, W.; Du, N.; Gu, Y.; Yin, J.; Liu, H.; Jia, X.; Huang, D.; et al. Hypoxia downregulated miR-4521 suppresses gastric carcinoma progression through regulation of IGF2 and FOXM1. Mol. Cancer 2021, 20, 9. [CrossRef]

13. Rupaimoole, R.; Calin, G.A.; Lopez-Berestein, G.; Sood, A.K. miRNA Deregulation in Cancer Cells and the Tumor Microenvironment. Cancer Discov. 2016, 6, 235-246. [CrossRef]

14. Kumar, S.; Vijayan, M.; Bhatti, J.S.; Reddy, P.H. MicroRNAs as Peripheral Biomarkers in Aging and Age-Related Diseases. Prog. Mol. Biol. Transl. Sci. 2017, 146, 47-94. [CrossRef] [PubMed]

15. Edbauer, D.; Neilson, J.R.; Foster, K.A.; Wang, C.F.; Seeburg, D.P.; Batterton, M.N.; Tada, T.; Dolan, B.M.; Sharp, P.A.; Sheng, M. Regulation of synaptic structure and function by FMRP-associated microRNAs miR-125b and miR-132. Neuron 2010, 65, 373-384. [CrossRef]

16. Fernandez-Hernando, C.; Suarez, Y. MicroRNAs in endothelial cell homeostasis and vascular disease. Curr. Opin. Hematol. 2018, 25, 227-236. [CrossRef] [PubMed]

17. Ell, B.; Kang, Y. MicroRNAs as regulators of bone homeostasis and bone metastasis. Bonekey Rep. 2014, 3, 549. [CrossRef]

18. Rajan, S.; Panzade, G.; Srivastava, A.; Shankar, K.; Pandey, R.; Kumar, D.; Gupta, S.; Gupta, A.; Varshney, S.; Beg, M.; et al. miR876-3p regulates glucose homeostasis and insulin sensitivity by targeting adiponectin. J. Endocrinol. 2018, 239, 1-17. [CrossRef] [PubMed]

19. Liu, B.; Shyr, Y.; Cai, J.; Liu, Q. Interplay between miRNAs and host genes and their role in cancer. Brief. Funct. Genom. 2018, 18, 255-266. [CrossRef]

20. Dohi, O.; Yasui, K.; Gen, Y.; Takada, H.; Endo, M.; Tsuji, K.; Konishi, C.; Yamada, N.; Mitsuyoshi, H.; Yagi, N.; et al. Epigenetic silencing of miR-335 and its host gene MEST in hepatocellular carcinoma. Int. J. Oncol. 2013, 42, 411-418. [CrossRef] [PubMed]

21. Wang, Z.; Yao, H.; Lin, S.; Zhu, X.; Shen, Z.; Lu, G.; Poon, W.S.; Xie, D.; Lin, M.C.; Kung, H.F. Transcriptional and epigenetic regulation of human microRNAs. Cancer Lett. 2013, 331, 1-10. [CrossRef]

22. O'Brien, J.; Hayder, H.; Zayed, Y.; Peng, C. Overview of MicroRNA Biogenesis, Mechanisms of Actions, and Circulation. Front. Endocrinol. 2018, 9, 402. [CrossRef] [PubMed]

23. Kang, L.; Han, C.; Yang, G.; Li, H.; Li, T.; Yang, S.; Liang, N.; Zhong, R.; Jia, L.; Zhu, D.; et al. miR-378 and its host gene Ppargclbeta exhibit independent expression in mouse skeletal muscle. Acta Biochim. Biophys. Sin. 2020, 52, 883-890. [CrossRef] [PubMed]

24. Stavast, C.J.; Erkeland, S.J. The Non-Canonical Aspects of MicroRNAs: Many Roads to Gene Regulation. Cells 2019, 8, 1465. [CrossRef] [PubMed]

25. Partin, A.C.; Zhang, K.; Jeong, B.C.; Herrell, E.; Li, S.; Chiu, W.; Nam, Y. Cryo-EM Structures of Human Drosha and DGCR8 in Complex with Primary MicroRNA. Mol. Cell 2020, 78, 411-422. [CrossRef] [PubMed]

26. Rice, G.M.; Shivashankar, V.; Ma, E.J.; Baryza, J.L.; Nutiu, R. Functional Atlas of Primary miRNA Maturation by the Microprocessor. Mol. Cell 2020, 80, 892-902. [CrossRef]

27. Bohnsack, M.T.; Czaplinski, K.; Gorlich, D. Exportin 5 is a RanGTP-dependent dsRNA-binding protein that mediates nuclear export of pre-miRNAs. RNA 2004, 10, 185-191. [CrossRef]

28. Olejniczak, M.; Kotowska-Zimmer, A.; Krzyzosiak, W. Stress-induced changes in miRNA biogenesis and functioning. Cell. Mol. Life Sci. 2018, 75, 177-191. [CrossRef]

29. Fareh, M.; Yeom, K.H.; Haagsma, A.C.; Chauhan, S.; Heo, I.; Joo, C. TRBP ensures efficient Dicer processing of precursor microRNA in RNA-crowded environments. Nat. Commun. 2016, 7, 13694. [CrossRef]

30. Catalanotto, C.; Cogoni, C.; Zardo, G. MicroRNA in Control of Gene Expression: An Overview of Nuclear Functions. Int. J. Mol. Sci. 2016, 17, 1712. [CrossRef]

31. Sarshad, A.A.; Juan, A.H.; Muler, A.; Anastasakis, D.G.; Wang, X.; Genzor, P.; Feng, X.; Tsai, P.F.; Sun, H.W.; Haase, A.D.; et al. Argonaute-miRNA Complexes Silence Target mRNAs in the Nucleus of Mammalian Stem Cells. Mol. Cell 2018, 71, 1040-1050. [CrossRef] 
32. Wong, J.J.; Ritchie, W.; Gao, D.; Lau, K.A.; Gonzalez, M.; Choudhary, A.; Taft, R.J.; Rasko, J.E.; Holst, J. Identification of nuclear-enriched miRNAs during mouse granulopoiesis. J. Hematol. Oncol. 2014, 7, 42. [CrossRef]

33. Dragomir, M.P.; Knutsen, E.; Calin, G.A. SnapShot: Unconventional miRNA Functions. Cell 2018, 174, 1038. [CrossRef] [PubMed]

34. Wang, W.X.; Prajapati, P.; Nelson, P.T.; Springer, J.E. The Mitochondria-Associated ER Membranes Are Novel Subcellular Locations Enriched for Inflammatory-Responsive MicroRNAs. Mol. Neurobiol. 2020, 57, 2996-3013. [CrossRef]

35. Sheu-Gruttadauria, J.; MacRae, I.J. Phase Transitions in the Assembly and Function of Human miRISC. Cell 2018, 173, 946-957. [CrossRef] [PubMed]

36. Cui, Y.; Lyu, X.; Ding, L.; Ke, L.; Yang, D.; Pirouz, M.; Qi, Y.; Ong, J.; Gao, G.; Du, P.; et al. Global miRNA dosage control of embryonic germ layer specification. Nature 2021. [CrossRef] [PubMed]

37. Banani, S.F.; Lee, H.O.; Hyman, A.A.; Rosen, M.K. Biomolecular condensates: Organizers of cellular biochemistry. Nat. Rev. Mol. Cell Biol. 2017, 18, 285-298. [CrossRef]

38. Spannl, S.; Tereshchenko, M.; Mastromarco, G.J.; Ihn, S.J.; Lee, H.O. Biomolecular condensates in neurodegeneration and cancer. Traffic 2019, 20, 890-911. [CrossRef] [PubMed]

39. Forman-Kay, J.D.; Kriwacki, R.W.; Seydoux, G. Phase Separation in Biology and Disease. J. Mol. Biol. 2018, 430, 4603-4606. [CrossRef]

40. Meister, G.; Landthaler, M.; Patkaniowska, A.; Dorsett, Y.; Teng, G.; Tuschl, T. Human Argonaute2 mediates RNA cleavage targeted by miRNAs and siRNAs. Mol. Cell 2004, 15, 185-197. [CrossRef]

41. Nishi, K.; Nishi, A.; Nagasawa, T.; Ui-Tei, K. Human TNRC6A is an Argonaute-navigator protein for microRNA-mediated gene silencing in the nucleus. RNA 2013, 19, 17-35. [CrossRef]

42. Turunen, T.A.; Roberts, T.C.; Laitinen, P.; Vaananen, M.A.; Korhonen, P.; Malm, T.; Yla-Herttuala, S.; Turunen, M.P. Changes in nuclear and cytoplasmic microRNA distribution in response to hypoxic stress. Sci. Rep. 2019, 9, 10332. [CrossRef]

43. Guo, H.; Pu, M.; Tai, Y.; Chen, Y.; Lu, H.; Qiao, J.; Wang, G.; Chen, J.; Qi, X.; Huang, R.; et al. Nuclear miR-30b-5p suppresses TFEB-mediated lysosomal biogenesis and autophagy. Cell Death Differ. 2021, 28, 320-336. [CrossRef]

44. Li, H.; Fan, J.; Zhao, Y.; Zhang, X.; Dai, B.; Zhan, J.; Yin, Z.; Nie, X.; Fu, X.D.; Chen, C.; et al. Nuclear miR-320 Mediates Diabetes-Induced Cardiac Dysfunction by Activating Transcription of Fatty Acid Metabolic Genes to Cause Lipotoxicity in the Heart. Circ. Res. 2019, 125, 1106-1120. [CrossRef] [PubMed]

45. Tong, M.; Sadoshima, J. Nuclear miR-320 Controls Lipotoxicity. Circ. Res. 2019, 125, 1121-1123. [CrossRef] [PubMed]

46. Fan, J.; Zhang, X.; Nie, X.; Li, H.; Yuan, S.; Dai, B.; Zhan, J.; Wen, Z.; Jiang, J.; Chen, C.; et al. Nuclear miR-665 aggravates heart failure via suppressing phosphatase and tensin homolog transcription. Sci. China Life Sci. 2020, 63, 724-736. [CrossRef]

47. Li, H.; Zhan, J.; Zhao, Y.; Fan, J.; Yuan, S.; Yin, Z.; Dai, B.; Chen, C.; Wang, D.W. Identification of ncRNA-Mediated Functions of Nucleus-Localized miR-320 in Cardiomyocytes. Mol. Ther. Nucleic Acids 2020, 19, 132-143. [CrossRef]

48. Zhan, J.; Lv, H.; Dai, B.; Yuan, S.; Fan, J.; Zhao, Y.; Yin, Z.; Wang, D.W.; Chen, C.; Li, H. The nuclear and cytoplasmic roles of miR-320 in non-alcoholic fatty liver disease. Aging 2020, 12, 22019-22045. [CrossRef]

49. Huang, V.; Place, R.F.; Portnoy, V.; Wang, J.; Qi, Z.; Jia, Z.; Yu, A.; Shuman, M.; Yu, J.; Li, L.C. Upregulation of Cyclin B1 by miRNA and its implications in cancer. Nucleic Acids Res. 2012, 40, 1695-1707. [CrossRef] [PubMed]

50. Di Mauro, V.; Crasto, S.; Colombo, F.S.; Di Pasquale, E.; Catalucci, D. Wnt signalling mediates miR-133a nuclear re-localization for the transcriptional control of Dnmt3b in cardiac cells. Sci. Rep. 2019, 9, 9320. [CrossRef]

51. Schwartz, J.C.; Younger, S.T.; Nguyen, N.B.; Hardy, D.B.; Monia, B.P.; Corey, D.R.; Janowski, B.A. Antisense transcripts are targets for activating small RNAs. Nat. Struct. Mol. Biol. 2008, 15, 842-848. [CrossRef] [PubMed]

52. Zhang, Y.; Fan, M.; Zhang, X.; Huang, F.; Wu, K.; Zhang, J.; Liu, J.; Huang, Z.; Luo, H.; Tao, L.; et al. Cellular microRNAs up-regulate transcription via interaction with promoter TATA-box motifs. RNA 2014, 20, 1878-1889. [CrossRef] [PubMed]

53. Xiao, M.; Li, J.; Li, W.; Wang, Y.; Wu, F.; Xi, Y.; Zhang, L.; Ding, C.; Luo, H.; Li, Y.; et al. MicroRNAs activate gene transcription epigenetically as an enhancer trigger. RNA Biol. 2017, 14, 1326-1334. [CrossRef] [PubMed]

54. Kang, M.; Tang, B.; Li, J.; Zhou, Z.; Liu, K.; Wang, R.; Jiang, Z.; Bi, F.; Patrick, D.; Kim, D.; et al. Identification of miPEP133 as a novel tumor-suppressor microprotein encoded by miR-34a pri-miRNA. Mol. Cancer 2020, 19, 143. [CrossRef] [PubMed]

55. Suzuki, H.I.; Young, R.A.; Sharp, P.A. Super-Enhancer-Mediated RNA Processing Revealed by Integrative MicroRNA Network Analysis. Cell 2017, 168, 1000-1014. [CrossRef]

56. Sabari, B.R.; Dall'Agnese, A.; Boija, A.; Klein, I.A.; Coffey, E.L.; Shrinivas, K.; Abraham, B.J.; Hannett, N.M.; Zamudio, A.V.; Manteiga, J.C.; et al. Coactivator condensation at super-enhancers links phase separation and gene control. Science $2018,361$. [CrossRef] [PubMed]

57. Klein, I.A.; Boija, A.; Afeyan, L.K.; Hawken, S.W.; Fan, M.; Dall'Agnese, A.; Oksuz, O.; Henninger, J.E.; Shrinivas, K.; Sabari, B.R.; et al. Partitioning of cancer therapeutics in nuclear condensates. Science 2020, 368, 1386-1392. [CrossRef]

58. Singh, I.; Contreras, A.; Cordero, J.; Rubio, K.; Dobersch, S.; Gunther, S.; Jeratsch, S.; Mehta, A.; Kruger, M.; Graumann, J.; et al. MiCEE is a ncRNA-protein complex that mediates epigenetic silencing and nucleolar organization. Nat. Genet. 2018, 50, 990-1001. [CrossRef]

59. Thulin, P.; Wei, T.; Werngren, O.; Cheung, L.; Fisher, R.M.; Grander, D.; Corcoran, M.; Ehrenborg, E. MicroRNA-9 regulates the expression of peroxisome proliferator-activated receptor delta in human monocytes during the inflammatory response. Int. $J$. Mol. Med. 2013, 31, 1003-1010. [CrossRef] 
60. Leucci, E.; Patella, F.; Waage, J.; Holmstrom, K.; Lindow, M.; Porse, B.; Kauppinen, S.; Lund, A.H. microRNA-9 targets the long non-coding RNA MALAT1 for degradation in the nucleus. Sci. Rep. 2013, 3, 2535. [CrossRef]

61. Wang, D.; Sun, X.; Wei, Y.; Liang, H.; Yuan, M.; Jin, F.; Chen, X.; Liu, Y.; Zhang, C.Y.; Li, L.; et al. Nuclear miR-122 directly regulates the biogenesis of cell survival oncomiR miR-21 at the posttranscriptional level. Nucleic Acids Res. 2018, 46, 2012-2029. [CrossRef]

62. Tang, R.; Li, L.; Zhu, D.; Hou, D.; Cao, T.; Gu, H.; Zhang, J.; Chen, J.; Zhang, C.Y.; Zen, K. Mouse miRNA-709 directly regulates miRNA-15a/16-1 biogenesis at the posttranscriptional level in the nucleus: Evidence for a microRNA hierarchy system. Cell Res. 2012, 22, 504-515. [CrossRef]

63. Henninger, J.E.; Oksuz, O.; Shrinivas, K.; Sagi, I.; LeRoy, G.; Zheng, M.M.; Andrews, J.O.; Zamudio, A.V.; Lazaris, C.; Hannett, N.M.; et al. RNA-Mediated Feedback Control of Transcriptional Condensates. Cell 2021, 184, 207-225. [CrossRef]

64. Li, X.; Fu, X.D. Chromatin-associated RNAs as facilitators of functional genomic interactions. Nat. Rev. Genet. 2019, 20, 503-519. [CrossRef]

65. Lauressergues, D.; Couzigou, J.M.; Clemente, H.S.; Martinez, Y.; Dunand, C.; Becard, G.; Combier, J.P. Primary transcripts of microRNAs encode regulatory peptides. Nature 2015, 520,90-93. [CrossRef]

66. Wang, J.; Zhu, S.; Meng, N.; He, Y.; Lu, R.; Yan, G.R. ncRNA-Encoded Peptides or Proteins and Cancer. Mol. Ther. 2019, 27, 1718-1725. [CrossRef] [PubMed]

67. Chen, P.B.; Chen, H.V.; Acharya, D.; Rando, O.J.; Fazzio, T.G. R loops regulate promoter-proximal chromatin architecture and cellular differentiation. Nat. Struct. Mol. Biol. 2015, 22, 999-1007. [CrossRef] [PubMed]

68. Saldana-Meyer, R.; Rodriguez-Hernaez, J.; Escobar, T.; Nishana, M.; Jacome-Lopez, K.; Nora, E.P.; Bruneau, B.G.; Tsirigos, A.; Furlan-Magaril, M.; Skok, J.; et al. RNA Interactions Are Essential for CTCF-Mediated Genome Organization. Mol. Cell 2019, 76, 412-422. [CrossRef] [PubMed]

69. Wang, J.; Choi, J.M.; Holehouse, A.S.; Lee, H.O.; Zhang, X.; Jahnel, M.; Maharana, S.; Lemaitre, R.; Pozniakovsky, A.; Drechsel, D.; et al. A Molecular Grammar Governing the Driving Forces for Phase Separation of Prion-like RNA Binding Proteins. Cell 2018, 174, 688-699. [CrossRef] [PubMed]

70. Ries, R.J.; Zaccara, S.; Klein, P.; Olarerin-George, A.; Namkoong, S.; Pickering, B.F.; Patil, D.P.; Kwak, H.; Lee, J.H.; Jaffrey, S.R. m (6) A enhances the phase separation potential of mRNA. Nature 2019, 571, 424-428. [CrossRef]

71. Yan, C.; Duanmu, X.; Zeng, L.; Liu, B.; Song, Z. Mitochondrial DNA: Distribution, Mutations, and Elimination. Cells 2019, 8, 379. [CrossRef]

72. Ro, S.; Ma, H.Y.; Park, C.; Ortogero, N.; Song, R.; Hennig, G.W.; Zheng, H.; Lin, Y.M.; Moro, L.; Hsieh, J.T.; et al. The mitochondrial genome encodes abundant small noncoding RNAs. Cell Res. 2013, 23, 759-774. [CrossRef]

73. Entelis, N.S.; Kolesnikova, O.A.; Martin, R.P.; Tarassov, I.A. RNA delivery into mitochondria. Adv. Drug Deliv. Rev. 2001, 49, 199-215. [CrossRef]

74. Mercer, T.R.; Neph, S.; Dinger, M.E.; Crawford, J.; Smith, M.A.; Shearwood, A.M.; Haugen, E.; Bracken, C.P.; Rackham, O.; Stamatoyannopoulos, J.A.; et al. The human mitochondrial transcriptome. Cell 2011, 146, 645-658. [CrossRef] [PubMed]

75. Sripada, L.; Singh, K.; Lipatova, A.V.; Singh, A.; Prajapati, P.; Tomar, D.; Bhatelia, K.; Roy, M.; Singh, R.; Godbole, M.M.; et al. hsa-miR-4485 regulates mitochondrial functions and inhibits the tumorigenicity of breast cancer cells. J. Mol. Med. 2017, 95, 641-651. [CrossRef] [PubMed]

76. Das, S.; Ferlito, M.; Kent, O.A.; Fox-Talbot, K.; Wang, R.; Liu, D.; Raghavachari, N.; Yang, Y.; Wheelan, S.J.; Murphy, E.; et al. Nuclear miRNA regulates the mitochondrial genome in the heart. Circ. Res. 2012, 110, 1596-1603. [CrossRef] [PubMed]

77. Macgregor-Das, A.M.; Das, S. A microRNA's journey to the center of the mitochondria. Am. J. Physiol. Heart Circ. Physiol. 2018, 315, H206-H215. [CrossRef]

78. McKenzie, A.J.; Hoshino, D.; Hong, N.H.; Cha, D.J.; Franklin, J.L.; Coffey, R.J.; Patton, J.G.; Weaver, A.M. KRAS-MEK Signaling Controls Ago2 Sorting into Exosomes. Cell Rep. 2016, 15, 978-987. [CrossRef]

79. Zeng, Y.; Sankala, H.; Zhang, X.; Graves, P.R. Phosphorylation of Argonaute 2 at serine-387 facilitates its localization to processing bodies. Biochem. J. 2008, 413, 429-436. [CrossRef]

80. Gusic, M.; Prokisch, H. ncRNAs: New Players in Mitochondrial Health and Disease? Front. Genet. 2020, 11, 95. [CrossRef]

81. Zhang, X.; Zuo, X.; Yang, B.; Li, Z.; Xue, Y.; Zhou, Y.; Huang, J.; Zhao, X.; Zhou, J.; Yan, Y.; et al. MicroRNA directly enhances mitochondrial translation during muscle differentiation. Cell 2014, 158, 607-619. [CrossRef]

82. Shepherd, D.L.; Hathaway, Q.A.; Pinti, M.V.; Nichols, C.E.; Durr, A.J.; Sreekumar, S.; Hughes, K.M.; Stine, S.M.; Martinez, I.; Hollander, J.M. Exploring the mitochondrial microRNA import pathway through Polynucleotide Phosphorylase (PNPase). J. Mol. Cell. Cardiol. 2017, 110, 15-25. [CrossRef] [PubMed]

83. Lin, C.L.; Wang, Y.T.; Yang, W.Z.; Hsiao, Y.Y.; Yuan, H.S. Crystal structure of human polynucleotide phosphorylase: Insights into its domain function in RNA binding and degradation. Nucleic Acids Res. 2012, 40, 4146-4157. [CrossRef]

84. Fan, S.; Tian, T.; Chen, W.; Lv, X.; Lei, X.; Zhang, H.; Sun, S.; Cai, L.; Pan, G.; He, L.; et al. Mitochondrial miRNA Determines Chemoresistance by Reprogramming Metabolism and Regulating Mitochondrial Transcription. Cancer Res. 2019, 79, $1069-1084$. [CrossRef] [PubMed]

85. Yan, K.; An, T.; Zhai, M.; Huang, Y.; Wang, Q.; Wang, Y.; Zhang, R.; Wang, T.; Liu, J.; Zhang, Y.; et al. Mitochondrial miR-762 regulates apoptosis and myocardial infarction by impairing ND2. Cell Death Dis. 2019, 10, 500. [CrossRef] [PubMed]

86. Lerner, R.S.; Seiser, R.M.; Zheng, T.; Lager, P.J.; Reedy, M.C.; Keene, J.D.; Nicchitta, C.V. Partitioning and translation of mRNAs encoding soluble proteins on membrane-bound ribosomes. RNA 2003, 9, 1123-1137. [CrossRef] 
87. Wu, P.H.; Isaji, M.; Carthew, R.W. Functionally diverse microRNA effector complexes are regulated by extracellular signaling. Mol. Cell 2013, 52, 113-123. [CrossRef]

88. Yang, X.; You, C.; Wang, X.; Gao, L.; Mo, B.; Liu, L.; Chen, X. Widespread occurrence of microRNA-mediated target cleavage on membrane-bound polysomes. Genome Biol. 2021, 22, 15. [CrossRef]

89. Kassan, M.; Vikram, A.; Li, Q.; Kim, Y.R.; Kumar, S.; Gabani, M.; Liu, J.; Jacobs, J.S.; Irani, K. MicroRNA-204 promotes vascular endoplasmic reticulum stress and endothelial dysfunction by targeting Sirtuin1. Sci. Rep. 2017, 7, 9308. [CrossRef]

90. Jeon, Y.J.; Kim, T.; Park, D.; Nuovo, G.J.; Rhee, S.; Joshi, P.; Lee, B.K.; Jeong, J.; Suh, S.S.; Grotzke, J.E.; et al. miRNA-mediated TUSC3 deficiency enhances UPR and ERAD to promote metastatic potential of NSCLC. Nat. Commun. 2018, 9, 5110. [CrossRef]

91. Xu, H.; Tian, Y.; Tang, D.; Zou, S.; Liu, G.; Song, J.; Zhang, G.; Du, X.; Huang, W.; He, B.; et al. An Endoplasmic Reticulum Stress-MicroRNA-26a Feedback Circuit in NAFLD. Hepatology 2020, 73. [CrossRef]

92. Lu, H.; Hu, J.; Li, J.; Lu, W.; Deng, X.; Wang, X. miR-328-3p overexpression attenuates the malignant proliferation and invasion of liver cancer via targeting Endoplasmic Reticulum Metallo Protease 1 to inhibit AKT phosphorylation. Ann. Transl. Med. 2020, 8 , 754. [CrossRef] [PubMed]

93. Zhou, N.; Qiao, H.; Zeng, M.; Yang, L.; Zhou, Y.; Guan, Q. Circ_002117 binds to microRNA-370 and promotes endoplasmic reticulum stress-induced apoptosis in gastric cancer. Cancer Cell Int. 2020, 20, 465. [CrossRef] [PubMed]

94. Liu, J.; Fan, L.; Yu, H.; Zhang, J.; He, Y.; Feng, D.; Wang, F.; Li, X.; Liu, Q.; Li, Y.; et al. Endoplasmic Reticulum Stress Causes Liver Cancer Cells to Release Exosomal miR-23a-3p and Up-regulate Programmed Death Ligand 1 Expression in Macrophages. Hepatology 2019, 70, 241-258. [CrossRef]

95. Yao, X.; Tu, Y.; Xu, Y.; Guo, Y.; Yao, F.; Zhang, X. Endoplasmic reticulum stress-induced exosomal miR-27a-3p promotes immune escape in breast cancer via regulating PD-L1 expression in macrophages. J. Cell. Mol. Med. 2020, 24, 9560-9573. [CrossRef]

96. Lee, Y.S.; Pressman, S.; Andress, A.P.; Kim, K.; White, J.L.; Cassidy, J.J.; Li, X.; Lubell, K.; Lim, D.H.; Cho, I.S.; et al. Silencing by small RNAs is linked to endosomal trafficking. Nat. Cell Biol. 2009, 11, 1150-1156. [CrossRef]

97. Gibbings, D.J.; Ciaudo, C.; Erhardt, M.; Voinnet, O. Multivesicular bodies associate with components of miRNA effector complexes and modulate miRNA activity. Nat. Cell Biol. 2009, 11, 1143-1149. [CrossRef]

98. Corradi, E.; Dalla, C.I.; Gavoci, A.; Iyer, A.; Roccuzzo, M.; Otto, T.A.; Oliani, E.; Bridi, S.; Strohbuecker, S.; Santos-Rodriguez, G.; et al. Axonal precursor miRNAs hitchhike on endosomes and locally regulate the development of neural circuits. EMBO J. 2020, 39, e102513. [CrossRef]

99. Kucherenko, M.M.; Shcherbata, H.R. miRNA targeting and alternative splicing in the stress response-Events hosted by membrane-less compartments. J. Cell Sci. 2018, 131. [CrossRef]

100. Gao, X.; Jiang, L.; Gong, Y.; Chen, X.; Ying, M.; Zhu, H.; He, Q.; Yang, B.; Cao, J. Stress granule: A promising target for cancer treatment. Br. J. Pharmacol. 2019, 176, 4421-4433. [CrossRef] [PubMed]

101. Molliex, A.; Temirov, J.; Lee, J.; Coughlin, M.; Kanagaraj, A.P.; Kim, H.J.; Mittag, T.; Taylor, J.P. Phase separation by low complexity domains promotes stress granule assembly and drives pathological fibrillization. Cell 2015, 163, 123-133. [CrossRef]

102. Emde, A.; Eitan, C.; Liou, L.L.; Libby, R.T.; Rivkin, N.; Magen, I.; Reichenstein, I.; Oppenheim, H.; Eilam, R.; Silvestroni, A.; et al. Dysregulated miRNA biogenesis downstream of cellular stress and ALS-causing mutations: A new mechanism for ALS. EMBO J. 2015, 34, 2633-2651. [CrossRef] [PubMed]

103. Si, W.; Ye, S.; Ren, Z.; Liu, X.; Wu, Z.; Li, Y.; Zhou, J.; Zhang, S.; Li, Y.; Deng, R.; et al. miR335 promotes stress granule formation to inhibit apoptosis by targeting ROCK2 in acute ischemic stroke. Int. J. Mol. Med. 2019, 43, 1452-1466. [CrossRef] [PubMed]

104. Si, W.; Li, Y.; Ye, S.; Li, Z.; Liu, Y.; Kuang, W.; Chen, D.; Zhu, M. Methyltransferase 3 Mediated miRNA m6A Methylation Promotes Stress Granule Formation in the Early Stage of Acute Ischemic Stroke. Front. Mol. Neurosci. 2020, 13, 103. [CrossRef] [PubMed]

105. Wang, X.; Chang, L.; Wang, H.; Su, A.; Wu, Z. Dcp1a and GW182 Induce Distinct Cellular Aggregates and Have Different Effects on microRNA Pathway. DNA Cell Biol. 2017, 36, 565-570. [CrossRef]

106. Jain, S.; Parker, R. The discovery and analysis of P Bodies. Adv. Exp. Med. Biol. 2013, 768, 23-43. [CrossRef]

107. Xie, D.; Chen, M.; Niu, J.; Wang, L.; Li, Y.; Fang, X.; Li, P.; Qi, Y. Phase separation of SERRATE drives dicing body assembly and promotes miRNA processing in Arabidopsis. Nat. Cell Biol. 2021, 23, 32-39. [CrossRef]

108. Riback, J.A.; Katanski, C.D.; Kear-Scott, J.L.; Pilipenko, E.V.; Rojek, A.E.; Sosnick, T.R.; Drummond, D.A. Stress-Triggered Phase Separation Is an Adaptive, Evolutionarily Tuned Response. Cell 2017, 168, 1028-1040. [CrossRef]

109. Franzmann, T.M.; Jahnel, M.; Pozniakovsky, A.; Mahamid, J.; Holehouse, A.S.; Nuske, E.; Richter, D.; Baumeister, W.; Grill, S.W.; Pappu, R.V.; et al. Phase separation of a yeast prion protein promotes cellular fitness. Science 2018, 359. [CrossRef]

110. Guo, Y.E.; Manteiga, J.C.; Henninger, J.E.; Sabari, B.R.; Dall'Agnese, A.; Hannett, N.M.; Spille, J.H.; Afeyan, L.K.; Zamudio, A.V.; Shrinivas, K.; et al. Pol II phosphorylation regulates a switch between transcriptional and splicing condensates. Nature 2019, 572, 543-548. [CrossRef]

111. Wang, Z.; Ma, Z.; Castillo-Gonzalez, C.; Sun, D.; Li, Y.; Yu, B.; Zhao, B.; Li, P.; Zhang, X. SWI2/SNF2 ATPase CHR2 remodels pri-miRNAs via Serrate to impede miRNA production. Nature 2018, 557, 516-521. [CrossRef] [PubMed] 